\title{
The psychologist and the posthumous assisted reproduction
}

\author{
Julieta Quayle* \\ Department of Preventive Medicine, Faculty of Medicine, University of São Paulo, Brazil
}

\begin{abstract}
The development of assisted reproductive techniques poses important challenges to the work of clinical psychologists. Due to its singularity, posthumous assisted reproduction, exponentially increases these challenges and engages the assisted reproduction team with social representations related to the process, bringing out ethical, important legal and moral issues. There are few studies related to this subject in Portuguese. The authors present data from some research that explore either the opinions about posthumous assisted reproduction or the difficulties inherent to this process, which is inscribed in a serious grief process. The risks related to the process are also presented. They discuss data they collected in a survey developed in social media (Facebook) and among students of a face to face assisted reproduction course, in order to get a grip on society's perceptions on the subject. They suggest guidelines to support the psychologist's work in this context with candidates to posthumous reproduction.
\end{abstract}

Lesley and John Brown had been trying to be parents for more than nine years. In 1978 they saw Louise born, conceived with the aid of assisted reproductive techniques. Since then, Louise has been known worldwide as the "first test-tube baby." This successful epic story inspired countless teams and transformed the world of parenthood forever.

Different actors have benefited from the use of these techniques since then. Among others, couples with fertility problems, women who want children without a partner; homoaffective couples; cancer patients wishing to cryopreserve their gametes for a later pregnancy; women who wanted to postpone motherhood for various reasons. Assisted reproduction (AR) began to help more people using the advances of medicine to fulfill their desire for parenthood.

Such a great change in parenthood maps requires the development of new institutional positions, formally or not. Social representations related to these situations have been gradually modified as individuals are put in contact (confronted?) with these new possibilities of parenting and its consequences. The emergence of prejudices, on the one hand, and unbridled hopes on the other, are only the extreme faces of the same coin, challenging individuals and institutions. The ethical and psychological repercussions are no less: to follow this true paradigm fissure requires different adaptations and defenses from the psyche, often installing small sectoral crises which are difficult to solve.

Our reflection here refers specifically to an aspect which is frequently hidden and ignored, relegated to the penumbra in assisted reproductive techniques (ART). The use of post mortem techniques, which offers the patient the possibility of having a biological child generated with the gamete of the beloved deceased person. In other words, the child who may be born from this procedure will have a deceased father or mother at the time of his conception and birth.

In Brazil, according to the Federal Council of Medicine (CFM), assisted reproduction post mortem or Posthumous Assisted Reproduction (PAR), is allowed, provided there is specific authorization of the deceased to use the cryopreserved biological material, in accordance with current legislation. This authorization must be included in a free and informed consent form, mandatory for all patients submitted to ART.
Because of technical aspects involved in the process (including the gestation), as well as in the collection of genetic material in emergency situations, most of the PAR requests are made by widowed women, according to scientific reports in the international literature. The rationale involved in the solicitation is associated with the personal need for maintenance of the "progeny project", despite the loss of the companion and often purported to "honor his will" (sic).

What moves these people to parenthood as the essential link in the elaboration of the loss, in the face of a mourning process? Some authors [1] propose that what drives these women is the love of the deceased, with whom they hoped to share their life and to form a family. What remains after the loss of the companion is the possibility of trying to overcome his absence with the conception and birth of an already much desired child. Allowing PAR seems, then, a good solution to the frustrated will and to overcome mourning and pain. In the case of the death of the wife, it is necessary to consider the insertion of another variable in the equation so that the RAR is feasible: the use of a replacement uterus [2], which adds more actors to the scene and demands even more care with legal and psychological aspects.

The sparse existing literature points to the potential harm to the child coming from the absence of the father in this context. That is, we would have on one hand, the right of a woman to procreation, even with her deceased husband, and on the other, a child deliberately conceived and brought up without the presence of an already deceased father. Literature regarding society's opinion about this procedure is scarce. Ueda et al. [3] carried out a study to verify the opinions of

${ }^{\star}$ Correspondence to: Julieta Quayle, Department of Preventive Medicine, Faculty of Medicine, University of São Paulo, Brazil, E-mail: jquayle@uol.com.br

Key words: psychology in assisted reproduction, assisted reproduction post mortem, posthumous assisted reproduction, assisted reproduction team, guidelines

Received: February 14, 2019; Accepted: February 28, 2019; Published: March 04,2019 
university students about posthumous reproduction in 32 university centers in Japan. In a poll of 3,719 respondents, they observed that $60 \%$ were favorable to the procedure.

A cross-sectional study carried out by Barton et al. [4] aimed at evaluating attitudes towards PAR in the United States. They used an electronic questionnaire that was offered to individuals who had registered as volunteers for online surveys in Zoomerang throughout the country. The 1049 participants (out of 1094 individuals invited) were between 18 and 75 years old. The results indicate that $47.8 \%$ supported the semen removal procedure in emergencies $(31.1 \%$ were opposed to this), while $42.7 \%$ favored the same procedure in relation to the female genetic material (35.9\%). Sixty-nine percent believed that prior consent of the deceased was necessary. Approval occurred more often among younger individuals with higher educational levels and income. As the other factors studied did not show a significant association with the opinions expressed (political party, religion, race, gender, region of the country, history of infertility). Individuals who were organ donors most often supported the procedure.

Hans \& Dooley [5] performed a telephone survey in the continental United States with 857 randomly selected respondents. The participants' ages ranged from 18 to 93 years $(M=50, S D=16)$. The majority of the sample consisted of women (62\%), married $(64 \%)$ and white $(85 \%)$. Half of the participants believed that the surviving partner should be able to use the genetic material of the partner, even in situations where the deceased's parents were against the process, or when the deceased's position was unknown. In all other situations, between two-thirds and three- quarters of the participants were in favor that the wishes of the survivor be followed.

Côté et al. [6] investigated the donation disposition of surplus embryos for the realization of PAR in third parties, based on data from informed consent in a public in vitro fertilization clinic in Canada. Four hundred fifty-eight terms Informed Consent (ICFs) were analyzed. Sixty-eight percent of the individuals consented to the use of these embryos for training embryologists or improvement of AR techniques while $56 \%$ consented to their use in research. Concerning PAR, the majority of patients ( $73 \%$ of men and $61.8 \%$ of women) agreed to leave their embryos to their partners for reproductive purposes in the event of their death.

An important aspect of this study was its emphasis on the projection of "real life context" prior to signing the Informed Consent Form (ICF). It is important to emphasize that this study indicates the existence of a significant minority of individuals who decline the option of PAR, suggesting that the fact that they are engaged in programs of assisted reproduction and desiring to become fathers and mothers while alive, is not a guarantee of their desire for both after his death. This indicates the need for a detailed TCLE, in which this option is actually discussed and not presented bureaucratically to couples under treatment for infertility.

One of the few follow-up studies available on PAR was performed by Raziel et al. [7] in Israel, with reference to the period from 2003 to 2010. They investigated the referral and outcome of the original request by the surviving spouse. Of the 21 deceased men with viable genetic material, 10 were single and 11 were married, with a mean age of 28.2 years (ranging from 19 to 51 years). In no case was there a subsequent request for the effective use of the genetic material (sperm) up to the time the article was written. This suggests that the demand for the withdrawal and conservation of the genetic material of the companion for PAR corresponds more to a decision of the moment than by a genuine desire to have a son of this companion after mourning. This may be mobilized by the fear of losing an opportunity and perhaps fed by the concern of not being able to have children of that companion in the future.

The authors aimed to informally evaluate the repercussions of the PAR in Brazilian media. Initially the launched the terms "assisted reproduction post mortem" in Google to investigate the main resonances in Portuguese. Almost all of the entries on the first 10 pages returned referred to texts related to law. This demonstrates that in the legal area there is a long-standing concern regarding the individual right to use this ART technique and study the repercussions on the succession law of the offspring thus generated. Few exceptions turned to the area of psychology (2), one of them from one of the authors [8], or bioethics (4). Symptomatically, there were no blogs or self-help pages in the Portuguese language, related to this topic.

We conducted an opinion survey using Facebook', and another, using the same questions, with professionals in the AR area who participated in a course. These two surveys were conducted in May 2018. The following are some of the most significant results of these surveys. There were one hundred and fifty-two people contacted through Facebook (FB). In the course of Psychology(C) that took place during the 4th Meeting of Psychology in Assisted Reproduction (held within the $3^{\text {rd }}$ Symposium on Human Reproduction and Genetics and the 3rd Multidisciplinary Conference on Rare Diseases), 42 of the 48 respondents answered the poll. The majority of participants were women $(\mathrm{FB}=86 \%, \mathrm{C}=80 \%)$, with postgraduate courses $(\mathrm{FB}=64 \%$, $\mathrm{C}=66 \%)$ or complete graduation $(\mathrm{FB}=29 \%, \mathrm{C}=28 \%$ In the $\mathrm{FB}$ group, $30 \%$ were psychologists and $11 \%$ worked in assisted reproduction. Therefore, these were not representative samples, either of the FB or the Brazilian population. Nevertheless, it represents the first attempt of probing opinions on the subject.

The majority of respondents were married or in a stable union $(\mathrm{FB}=65 \%, \mathrm{C}=65 \%$, Figure 1), aged $31-40$ years (FB: $30 \%, \mathrm{C}: 45 \%$, Figure 2). In the FB group, 55\% had no children (55\%); $53 \%$ wanted to have them, while $38 \%$ did not want children, and $9 \%$ said they had not thought about them yet. These last questions were not asked to the course participants. When asked if they knew what PAR was, most said yes $(\mathrm{FB}=45 \%, \mathrm{C}=76 \%)$, although a significant proportion reported not being sure, as shown in Figure 3.

There are divergent opinions about whether these procedures should be performed or not. The majority $(\mathrm{FB}=58 \%, \mathrm{C}=61 \%)$ believe that this depends on the situation, while a minority $(\mathrm{FB}=11 \%, \mathrm{C}=9 \%)$ is against them in all contexts. A significant proportion is in favor, regardless of the circumstances $(\mathrm{FB}=20 \%, \mathrm{C}=19 \%)$ and some have no formed opinion $(\mathrm{FB}=10 \%, \mathrm{C}=9 \%)$. Almost all $(\mathrm{FB}=94 \%, \mathrm{C}=95 \%)$ consider that the donor's prior consent for the use of genetic material is necessary. The similarity of the proportions of respondents in the two groups in relation to proposed alternatives is highlighted, which may be associated with the profile of friends and followers of the authors in FB who participated in the survey: frequently in the health area and with a postgraduate degree.

Among those who oppose the procedure, the fact that the child is born with one of the parents already dead is presented as a justification, as well as the fact that the procedural is "unnatural". Some used justifications for that position follow: "I do not think it is a healthy way of dealing with mourning"; or "A baby with the DNA of your deceased partner does not replace him." Similarly, "I think a lot of expectations would be placed on the child. He will come to the world to attend to 


\section{Respondents Marital Status}

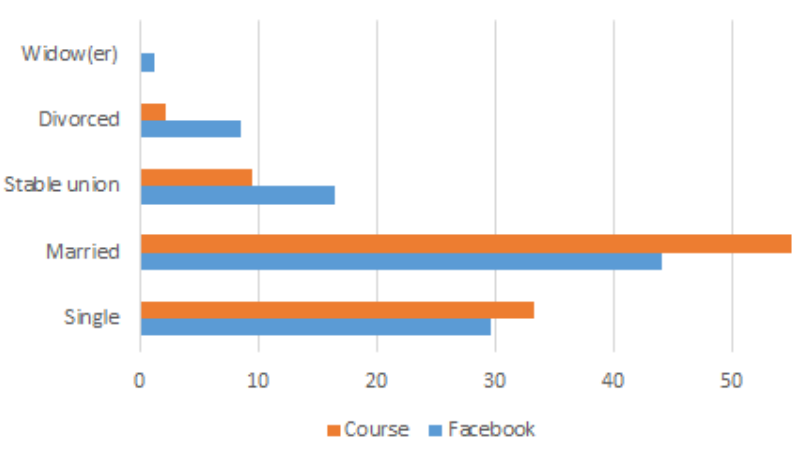

Figure 1. Distribution of respondents according to marital status

\section{Respondents by age group}

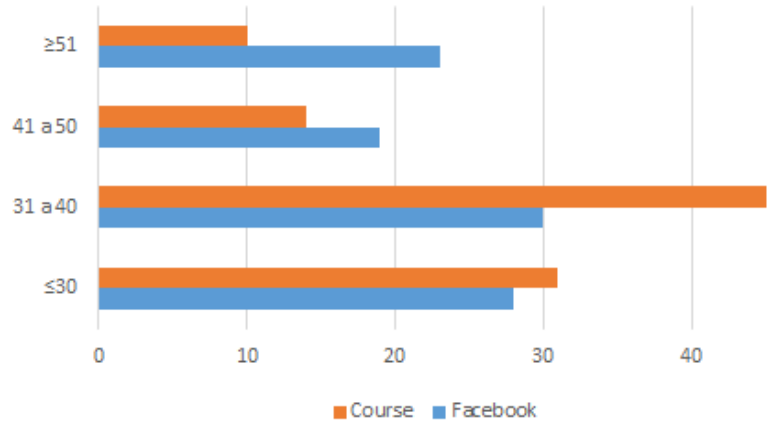

Figure 2. Distribution of respondents according to age group

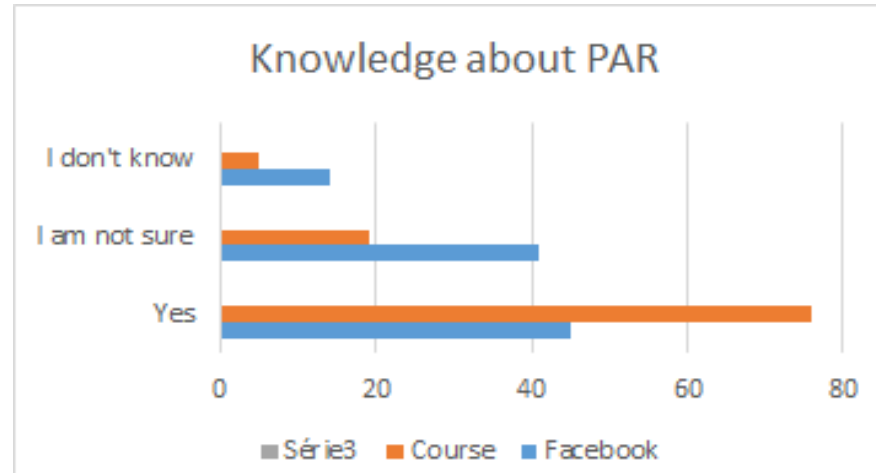

Figure 3. Distribution of the respondents in relation to the knowledge of PAR

whose wishes? ". Or again: "Strange ... unnatural (...) changes the order of things! What will it be like to be the child of a memory? It is an act of selfishness toward the child who is born of probable sadness." Or, "The person is already dead, will not be part of the baby's life. This reflects much more a desire of the adult toward himself than to think of that child that will be generated."

The strength of these sentences point out the difficulty of accepting this choice, even by people who accept some other "unnatural" medical procedures, like surgeries, or even other kinds of assisted reproduction techniques. Although the birth of children after the death of the father or associated to the death of a parturient is not something new in our civilization (mainly due to different situations of violence), this experience stems from uncontrolled and unplanned situations. In the case of PAR, parenting is actively sought in a critical context of mourning.
Among those who expressed favorable opinions, the existence of a AR treatment and documentation assuring the position of the deceased are important justifications. The perception of the existence of an earlier parenting project is associated with greater understanding of the search for a child after the death of one of the partners. The previous conservation of genetic material was also considered as a kind of tacit agreement for the possibility of PAR. The "solitary" search sometimes linked to the absence of children received little approval and was strongly questioned. The age factor was not considered relevant by any of the respondents. Approximately 10\% didn't answer these questions. Table 1 presents a description of the frequency of these responses.

Another aspect investigated was the need for some time lag between the partner's death and the procedure. The majority ( $\mathrm{FB}=$ $44 \%, C=61 \%$ ) answered yes, $38 \%$ said no, and $17 \%$ said they did not know what to think about it. Among the 87 participants who advocated the existence of this interval on FB, $62 \%$ evaluated that this depended on each case and $31 \%$ proposed a normative period of 1 year. In group $\mathrm{C}$, of the 20 who advocated the existence of this interval, 33\% evaluated that this depended on each case and 16\% also proposed 1 year. Figure 4 illustrates these responses.

Considering the need for prior consent to obtain genetic material or to use cryopreserved genetic material in PAR situations, the majority ( $\mathrm{FB}=94 \%, \mathrm{C}=95 \%)$ of the participants consider it necessary. We also inquired about the risk perception related to the procedure. The majority responding affirmatively $(\mathrm{FB}=60 \%, \mathrm{C}=66 \%$ ) while a few responded negatively $(\mathrm{FB}=23 \%, \mathrm{C}=16 \%$ ); a similar proportion reported not knowing what to answer $(\mathrm{FB}=17 \%, \mathrm{C}+16 \%)$. A list was presented with possible risks to check all the alternatives, which corresponded to respondents' perception. These choices are presented in table 2, considering the number of answers (not respondents) as reference.

Table 1. Respondents opinions about acceptable conditions for PAR

\begin{tabular}{|l|c|c|c|c|}
\hline \multirow{2}{*}{ Reasons for PAR } & \multicolumn{2}{|c|}{ Facebook } & \multicolumn{2}{|c|}{ Course } \\
\cline { 2 - 5 } & for man & $\begin{array}{c}\text { for } \\
\text { women }\end{array}$ & for man & $\begin{array}{c}\text { for } \\
\text { women }\end{array}$ \\
\hline When couple was already in AR treatment & 75 & 72 & 19 & 17 \\
\hline When there is documentation & 43 & 39 & 29 & 30 \\
\hline Didn't answer & 15 & 18 & 8 & 8 \\
\hline When person previously cryopreserved genetic material & 8 & 10 & 13 & 10 \\
\hline When the widow/er does not have children & 6 & 3 & 9 & 8 \\
\hline When it is possible to obtain adequate material & 5 & 7 & 5 & 5 \\
\hline Depends on the widow's age & 0 & 0 & 4 & 0 \\
\hline Other situations & 2 & 3 & 0 & 5 \\
\hline
\end{tabular}

\section{Time interval for PAR}

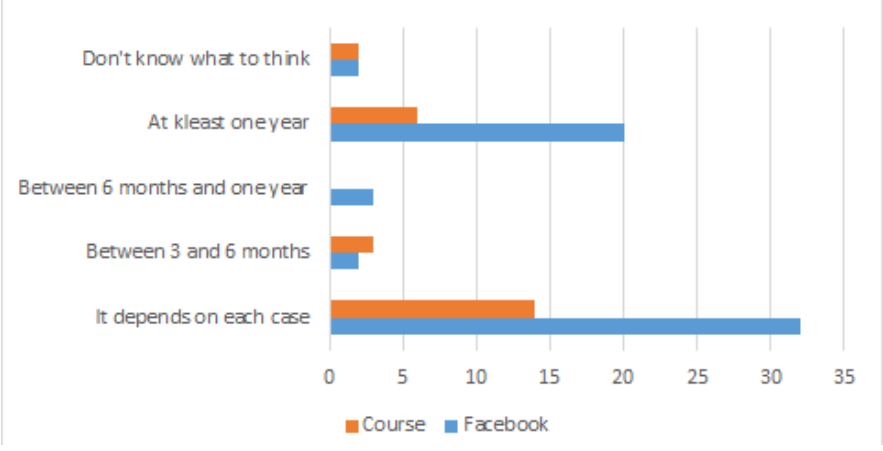

Figure 4. Proposal of time interval for the performance of PAR 
One of the last questions investigated if the participant had discussed or not with his family and / or friends his/her willingness to donate organs. The majority ( $\mathrm{FB}=85 \%, \mathrm{C}=88 \%$ ) answered affirmatively. When the same question referred to the same but related to donating genetic material, the majority $(\mathrm{FB}=91 \%, \mathrm{C}=83 \%)$ responded negatively. This suggests the difficulty in approaching this subject even with relatives, a topic still permeated by prejudices and negative social representations. The preference of the participant was also verified by hypothesizing PAR for themselves. A minority $(\mathrm{FB}=6 \%, \mathrm{C}=5 \%)$ would accept this alternative, while similar proportions of participants believed that this decision should be left to the surviving spouse ( $\mathrm{FB}=$ $37 \%, \mathrm{C}=45 \%)$ or disapproved the idea $(\mathrm{FB}=36, \mathrm{C}=45 \%)$.

The data of these polls suggest that the subject in Brazil still refers to taboos and negative social representations, possibly due to perceived proximity to death. PAR is perceived as a way to overcome traditional barriers, which associates morbidly with the attempts of manipulating destiny. Although PAR is recognized as a right of the individual, in "politically correct" attitudes and responses, the proposal of important restrictions to its implementation, alleging, mainly, the well-being of the child who would be born as a result of the process points to worries and prejudice (Figure 5).

The consideration of a waiting period for the procedure to be carried out among those who are favorable to the procedure is also an indicator of caution, suggesting that the passage of time and the mourning process may lead to different decisions by the survivor, as suggested by the study by Raziel et $\mathrm{al}^{7}$. The uniqueness of PAR calls for psychological assessment of the origins and potential repercussions of the procedure on a case-by-case basis, not in the sense of indicating or contraindicating the procedure, but rather in favoring a conscious and critical decision-making, taking into account the well-being of all involved.

Table 2. Risk Perception related to PAR

\begin{tabular}{|l|c|c|c|c|}
\hline Types of risk & \multicolumn{2}{|c|}{ Facebook } & \multicolumn{2}{|c|}{ Course } \\
\hline Risks in PAR itself & $\mathrm{N}$ & $\%$ & $\mathrm{~N}$ & $\%$ \\
\hline Psychological risks for the patient & 84 & $22 \%$ & 23 & $23 \%$ \\
\hline Psychological risks for the child & 73 & $19 \%$ & 19 & $19 \%$ \\
\hline Risk that the procedure does not work & 55 & $14 \%$ & 10 & $10 \%$ \\
\hline Risks of miscarriage or unhealthy baby & 37 & $9 \%$ & 10 & $10 \%$ \\
\hline Risks of child not being accepted by society & 12 & $3 \%$ & 4 & $4 \%$ \\
\hline Risks to donor health & 10 & $2 \%$ & 3 & $3 \%$ \\
\hline Risks of child not being accepted by deceased's family & 46 & $12 \%$ & 14 & $14 \%$ \\
\hline Risks of child not having right to inheritance & 26 & $7 \%$ & 7 & $7 \%$ \\
\hline Risks of child not being able to add deceased's name & 48 & $12 \%$ & 10 & $10 \%$ \\
\hline
\end{tabular}

\section{Opinions about PAR procedures for oneself}

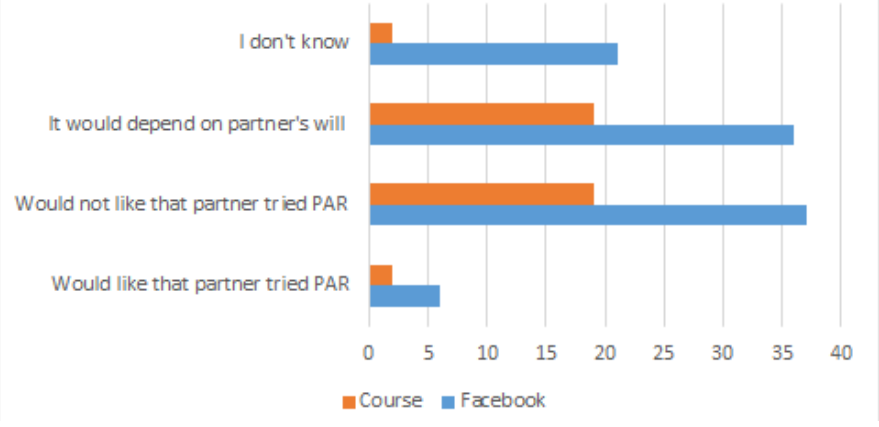

Figure 5. Opinion of respondents about PAR for themselves

\section{The repercussions}

The study of the repercussions of PAR in the psyche, as well as the importance of the assessment and follow-up of individuals, couples and families, by a mental health professional, is a consensus among specialists. The provision of a space for listening and reflection is fundamental to elaborate the psychic suffering usually associated with situations of biological or social infertility. It is no different in the case of PAR. Quayle and Dornelles [8] consider that "programmed orphanhood (implied in the PAR) occupies a locus in the fabric and in the wide family network and, even when there is formal signed authorization of the donor of the genetic material for its use, it is necessary to understand the contingencies under which the process of subjectivation of this child begins, its mission, its history. "

It is necessary for the applicant to understand his conscious motivations and what else moves him/her to this action -his/her desire. It is essential to reflect on the benefits and difficulties of raising a child of a deceased person, as well as to reflect on the conditions of the child conceived under such extraordinary circumstances and intended to hold, in a certain way, a special position in family dynamics [9]. A pregnant woman may lose her husband and have to raise her child alone. But in PAR there is a specific choice (more or less conscious) for continuing a project previously made by the couple and assumed by the surviving spouse. It is very important that this is clear, and that this survivor can assess whether this demand really makes sense, has meaning by itself and does not correspond to a decision mobilized primarily due to pain and mourning.

Other questions arise. Within the scope of family law, one must think about relevant topics, such as recognition of membership, inheritance and patrimony. It seems that there is still no consensus on the subject, but the consent form signed by the deceased affirming his will - that his gamete be used by his / her mate in case something happens to him - is of extreme necessity for the validation of these rights. Some of the repercussions in the extended family are often associated with perceptions or fantasies that the pursuit of this form of AR is mobilized exclusively for financial reasons, especially if the couple did not have children yet.

On the other hand, we can discuss whether the term signed by the deceased by himself, thinking in emotional terms, is a necessary and sufficient condition to conclude that the surviving partner can continue with the treatment. It is common for the paper to be signed without the individuals evaluating all possible consequences - for example, the difficulty of giving a destiny to surplus embryos. For all these reasons, it is essential that the RA team consider the moment that partner is living when making the choice to use post-mortem insemination. During the process of mourning perhaps one should not make such important decisions.

From an ethical point of view, the postmortem RA highlights the principle of autonomy (of the interested party) and of the beneficence (of the child). There may be conflict between these two propositions and international committees, such as ESHRE, suggest promoting autonomous decision-making, but accompanied by counseling and / or psychotherapy, could be the best way to deal satisfactorily with this conflict.

\section{The psychologist's intervention in PAR}

The participation of psychology professionals in the assisted reproduction processes is strongly recommended by expert committees around the world and it is a reality in most AR centers. Some guidelines 
are proposed for PAR. The European Society of Human Reproduction and Embryology- ESHRE Committee [10], for example, emphasizes that a minimum period of one year should be respected for the procedure and that the applicant should receive counseling during that period ("the partner receives extensive counseling"). This monitoring presupposes not only the offer of differentiated listening, but also the investigation of the motivation of the person interested, as well as help in the decision making.

In a recent work Lawson et al. [11] emphasized that it is important to investigate, whenever possible, whether the desire for posthumous RA relates to needs related to parenting and to the perspective of a child that can, in a certain way (re) validate a relationship, or if it is the result of a poorly elaborated grieving process and the difficulty in accepting the death of the partner. They performed a survey on the scarce literature about the so-called "psychological risks" associated with the procedure. They point out that among these risks should be considered the situations of non-agreement in the family about the realization of AR, which can lead to legal problems, stress and conflicts, also involving the child thus conceived.

The possibility of additional losses associated with AR and the gestational experience (gestational losses, fetal deaths, malformations and genetic fetal syndromes, etc.) should also be considered and discussed, as well as the consequent single parenting and its repercussions on the physical and emotional state of the mother and the child [12]. These authors question whether children conceived in PAR can end up assuming a vicarious function of the "substitute" of a missing/gone figure, similar to that observed in children born after the death of an older sibling, bringing difficulties of establishing one's identity. Other data suggest, however, that it is possible for children to deal with the situation in a similar way of others who have lost their parents when they are very young. However, in strong terms, Landau (quoted by Lawson et al. [11]) understands that PAR creates "planned orphans," and that this situation is not necessarily comparable to that of other children in whom the loss was accidental.

Mourning situations bring death to our daily reality, put us closer to our vulnerability and the fragility of the human condition. However, it also brings us closer to our strength and vitality, the will we have to live [13]. It helps to resize the variables involved and the very elaboration of loss and mourning. The psychologist inserted in the multiprofessional team, either in institutions or in a private practice, should offer a "potential space" so that the patient can construct a "new knowledge", the knowledge that narrating his/her experience and history makes possible. It is important that the practitioner can help the patient to think about some important issues: what space will the child who comes from the treatment occupy in the future mother / family life? Will it fill a void? Heal a wound? Manically deny death? Retrieve hope? Give meaning to life? What is expected?

It is fundamental that the professional listens to the patient, respecting the rhythm and characteristics [14]. The loss of the loved one is painful to deal with. In psychic terms we know that it is of the utmost importance that a woman can make a decision when the most painful aspects of mourning are over. Then she will be able to make objective decisions, but with emotional significance, after being able to rebuild her life. Dying has no age, no time, and leaves us with a void that seems to invade our chest and soul. The end of something is almost always a very painful process. We cannot change this path, but we can make sense of suffering. "In pain we find an honesty that is not present in any other feeling [15]."
RA treatment is not easy and does not provide certainty of pregnancy or its satisfactory development, in any context. Here it is the same. The bereaved patient will still have to face the uncertainty of a positive outcome and deal with another anguish and pain if the outcome of the treatment is negative. Thus, other real and symbolic losses can result even when attempting this redemption and re-signification. Even with a positive result, it must be considered that the woman might still be living in mourning - death, along with pregnancy - life, and this in itself can bring moments of anguish to the pregnant woman, as well as moments of hope. This ambivalence can bring complications, since gestation is culturally considered a moment of deep joy and fullness. To perceive oneself in disagreement with these rules can be deeply distressing. The patient may feel alone and sometimes abandoned.

ESHRE (2006) recommendations can serve as a reference for the performance of the team and the psychology professional. They, as well as the guidelines of the "First Brazilian Consensus on Psychology in Assisted Reproduction"[16] and the regulations of the Federal Council of Medicine [17], supported the authors' proposals for the elaboration of recent Brazilian recommendations sponsored by Sociedade Brasileira de Reprodução Assistida - SBRA [18] on this subject. Among them, we emphasize the importance of a realistic presentation of the risks and benefits of the process. The orientation of couples about the importance of the free and informed consent form, which is much more than mere formality, is fundamentally prophylactic.

Thus, before (or beyond), opting for PAR, the patient must mourn the loss of the deceased partner. Psychological counseling provides the conditions for this and favors patient's well-being. It also allows for the experience of living with pain, but without psychological suffering. And pain without suffering is called "saudade", in Portuguese. Something you miss in a tender way. As distressing as a loss is, we have the ability to regenerate ourselves and move on. "Life and death: we met the paradox. If we are closer to death, we are closer to life. This is what we see as we mature. Losses occur from the beginning of our lives, from the most mundane to the most striking and, sometimes, traumatizing" [13]. As difficult as it is, one has to move on to make a choice here.

\section{References}

1. Dantas E, Raposo VL (2012) Legal aspects of post-mortem reproduction: a comparative perspective of French, Brazilian and Portuguese legal systems. Med Law 31:181-198. [Crossref]

2. Bahadur G (2002) Death and conception. Hum Reprod 17: 2769-2775. [Crossref]

3. Ueda N, Kushi N, Nakatsuka M, Ogawa T, Nakanishi Y, et al. (2008) Study of views on posthumous reproduction, focusing on its relation with views on family and religion in modern Japan. Acta Med Okayama 62: 285-296. [Crossref]

4. Barton S (2012) Population-based study of attitudes toward posthumous reproduction. Fertil Steril 98: 735-740. [Crossref]

5. Hans JD, Dooley B (2014) Attitudes Toward Making Babies with a Deceased Partner's Cryopreserved Gametes. Death Stud 38: 571-581. [Crossref]

6. Côté S, Affdal AO, Kadoch IJ, Hamet P, Ravtsk V (2014) Posthumous reproduction with surplus in vitro fertilization embryos: a study exploring users' choice. Fertil Steril 102: 1410-1415. [Crossref]

7. Raziel A, Friedler S, Strassburger D, Kaufman S, Umansky A, et al. (2011) Nationwide use of postmortem retrieved sperm in Israel: a follow-up report. Fertil Steril 95: 26932695. [Crossref]

8. Quayle J, Dornelles LM (2015) Monoparentalidade programada e reprodução assistida: da "produção independente" à utilização de sêmen post mortem. Mudanças Psicologia da Saúde 23: 31-40.

9. Quayle J, Santos J (2018) Reprodução Assistida Post Mortem - possibilidades de atenção psicossocial. IN: Straube, KM MELAMED, R.M.M. Reprodução Assistida. Guia de Recomendações em atenção psicossocial em centros de reprodução assistida. SBRA-Soul: São Paulo. 
10. ESHRE Task Force on Ethics and Law, Pennings G, de Wert G, Shenfield F, Cohen J, et al. (2011) ESHRE Task Force on Ethics and Law 11: Posthumous assisted reproduction. Hum Reprod 21: 3050-3053. [Crossref]

11. Lawson AK, Zweifel JE, Klock SC (2016) Blurring the line between life and death: a review of the psychological and ethical concerns related to posthumous-assisted reproduction. Eur J Contracept Reprod Health Care 21: 339-346. [Crossref]

12. Schellinski K (2014) Who am I? J Anal Psychol 59: 189-210. [Crossref]

13. Motta IF, Andriatte AM, Gressle G (2017) Conversando sobre luto com adultos e crianças: a ciranda do viver/morrer. Curitiba: Artêra.
14. Lescovar GZ (2004) As consultas terapêuticas e a psicanálise de D. Winnicott. Estudos de Psicologia Campinas 21: 43-61.

15. Carpinejar F (2014) Me ajude a chorar. $3^{\mathrm{a}}$ ed. Rio de Janeiro. Bertrand Brasil.

16. Sociedade Brasileira de Reprodução Assistida (SBRA) (2013) $1^{\circ}$ Consenso de Psicologia em Reprodução Assistida. São Paulo/Rio de Janeiro: Livre Expressão.

17. Conselho Federal De Medicina (CFM) (2017) Resolução 2.168/2017, Brasilia, CFM.

18. Quayle J, Dornelles LM (2013) Questões atuais: doação de embriões, monoparentalidade programada e vida sem filhos. In: Sociedade Brasileira de Reprodução Assistida (SBRA) $1^{\circ}$ Consenso de Psicologia em Reprodução Assistida. São Paulo/Rio de Janeiro: Livre Expressão.

Copyright: (O2019 Quayle J. This is an open-access article distributed under the terms of the Creative Commons Attribution License, which permits unrestricted use, distribution, and reproduction in any medium, provided the original author and source are credited. 